ECCOMAS

Proceedia
COMPDYN 2021

$8^{\text {th }}$ ECCOMAS Thematic Conference on Computational Methods in Structural Dynamics and Earthquake Engineering

M. Papadrakakis, M. Fragiadakis (eds.)

\title{
EXPLORING THE EXPECTED INCREASE OF COSTS AND LOSS REDUCTION BY RAISING THE BAR IN SEISMIC DESIGN: COMPARISON OF ALTERNATIVE DESIGN METHODOLOGIES AND EARTHQUAKE-RESISTANT TECHNOLOGIES
}

\author{
Francesca Gentili ${ }^{1}$, Jonathan Ciurlanti ${ }^{1}$, Simona Bianchi ${ }^{1}$, Stefano Pampanin ${ }^{1}$ \\ ${ }^{1}$ Sapienza University of Rome, \\ Department of Structural and Geotechnical Engineering, Via Eudossiana 18, 00184, Rome, Italy \\ gentili.1652702@studenti.uniroma1.it, jonathan.ciurlanti@uniroma1.it, \\ simona.bianchi@uniroma1.it, stefano.pampanin@uniroma1.it
}

\begin{abstract}
The severe socio-economic impact of recent earthquakes has further highlighted the existing mismatch between societal expectations and reality of seismic performance of modern buildings. Targeting the traditional Life-Safety level is not enough when dealing with new building design, thus the seismic scientific community is currently aiming to raise the bar in terms of seismic/structural safety. To achieve this goal, different strategies might be adopted, as implementing more advanced design methodologies, increasing the seismic demand (design) level and/or switching from a traditional/monolithic building system to an innovative high performance low-damage structure, capable to withstand high levels of shaking without being (significantly) damaged. Based on this motivation, the paper aims at comparing - through a parametric study - the cost/performance of Reinforced Concrete case-study buildings designed for increasing level of seismic intensity (low-to-high) according to: a) alternative design approaches (force-based vs displacement-based) and b) different earthquake-resisting technologies (monolithic vs low-damage). Thirty-seven parametric configurations are investigated. Analytical/numerical investigations are carried out to determine the building capacity curves and loss assessment investigations are performed to compute the Expected Annual Losses (EAL). Results highlight the convenience of a displacement-based design approach, allowing for a better control of the building performance in the plastic domain, as well as of the adoption of a low-damage technology, leading to a very high performance and significantly reduced economic losses for a small increase of the initial investment costs.
\end{abstract}

Keywords: Performance-based, Seismic safety, Displacement-based design, Low damage, Post-earthquake losses. 


\section{INTRODUCTION}

The current performance-based seismic design of new buildings is based on the acceptance of severe level of damage in buildings after major (design level) earthquakes. When subjected to seismic shakings, multi-story structures are expected to concentrate the inelastic demand (therefore damage for traditional technology) in plastic hinges zones located at the end sections of the structural members, according to the hierarchy of strengths or capacity design principles (Figure 1a). Furthermore, according to a Life Safety design approach, attention is typically given to the structural skeleton only, whilst non-structural elements can be very vulnerable and consequently susceptible to high level of damage under low-to-moderate intensity earthquakes. Recent seismic events, in particular the Christchurch earthquake 2011 [1], have further highlighted the limits of this traditional design approach. Although modern buildings behaved as expected, resisting to even higher than code design-level earthquakes, with no collapse and safeguarding humane life, severely damaged buildings were often deemed too expensive to be repaired and were demolished. Targeting the Life-Safety objective is thus not enough when dealing with new building design. As a matter of fact, in recent years research is raising the bar in seismic design aiming at enhanced structural/seismic safety levels for our modern structures in order to fulfil the society demand in terms of seismic resilience, avoiding massive consequences in terms of socio-economic losses.

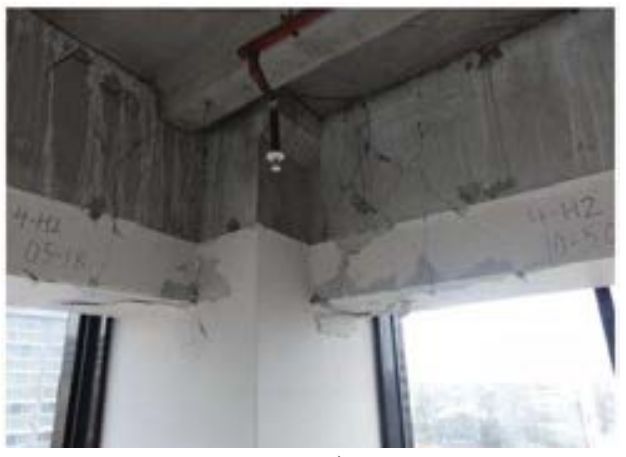

a)

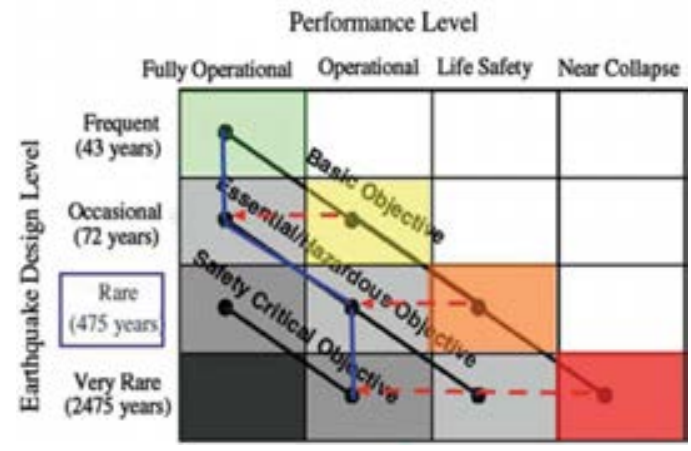

b)

Figure 1. a) Example of beam plastic hinge from a 22 story RC Building [1]; b) Seismic performance design objective matrix [2] modified to emphasise a damage-control objective and design philosophy [3,4].

To reach this aim, different strategies might be adopted to improve the seismic safety and economic resilience of buildings (and communities) as 1) implementing more appropriate and advanced design methodologies and/or 2) increasing the seismic demand design level and/or 3) adopting high-performance earthquake-resistant solutions. In such context, growing attention has been recently dedicated to the development of innovative damage-mitigation technologies, aiming at the control and reduction of the post-earthquake damage. Apart from well-known advanced technologies such as base isolation and supplemental dissipative braces, particular interest is being received by more recently developed "low-damage" systems, based on posttensioned rocking mechanisms, the so-called PRESSS technology (PREcast Seismic Structural System) for concrete structures $[5,6,7,8]$. This moment-resisting system combines self-centering capacity, through post-tensioned bars/tendons in the structural elements, and dissipating capabilities, provided either by internally located mild steel bars - as per the first generation of this technology - or using externally replaceable dissipaters, more recently developed [9]. The system behavior results in a dissipative and re-centering Flag-Shape hysteresis cycle [10] allowing for negligible permanent deformations after earthquakes. 
Nevertheless, a common obstacle to the wider application of advanced seismic design methodologies and innovative low-damage technologies is often the uninformed perception/prejudice that such approaches would lead to substantially higher and unaffordable costs. Furthermore, rarely the economic benefits associated to a significantly reduced level of damage and thus direct and indirect losses, are computed. This paper intends to shed a light on this important topic, providing robust evidences for informed decision-making on the opportunity (and associated solutions) to raise the bar towards more resilient communities.

\section{RESEARCH OUTLINE}

Based on the above discussion, this work fits into the context of society's growing need for safer and more economically resilient buildings and aims to prove the beneficial effects of designing in a more conscious and controlled way. These objectives are pursued through a parametric study intended to compare the cost/performance of different case-study buildings with different design parameters, design methods, and/or construction technologies. A summary of all the resilient-enhanced strategies and cases investigated within this paper are summarized in the following Figure 2.

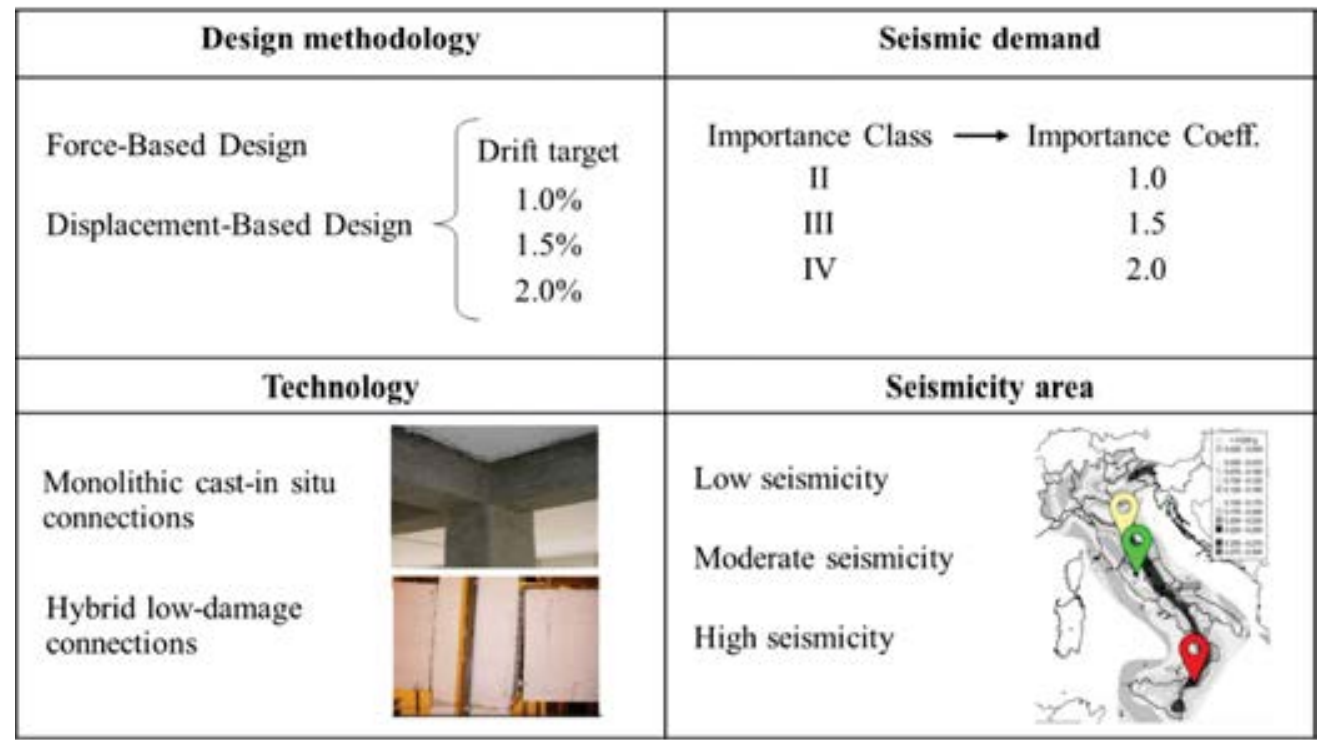

Figure 2: Summary of resilient-enhanced strategies and cases involved in the study.

Alternative design methods are adopted, namely the traditional Force-Based Design (FBD) and the more recently developed and advanced Direct Displacement-Based Design (DDBD), in order to highlight that a design based on (targeting and thus controlling/limiting) displacements rather than forces allows to better control the performance of buildings in the plastic domain. The FBD is implemented following the prescriptions of the Italian code, NTC 2018 [11], thus the method is based on the calculation of the natural period of the structure by alternative formulations and on the choice of the behavior factor, q, depending on the structural typology, its statically indeterminate level and the design criteria (ductility class). These assumptions do not allow to properly control the building structural behavior. On the other hand, the DDBD method [12] is based on the initial choice of a target drift, thus the seismic behavior/performance of the structure is controlled upfront by the designer and his design choice. 
In addition to the two different design methodologies, the increase of seismic safety is studied through the variation of the Importance Level or Class (II, III, IV, i.e. from ordinary/residential buildings to strategic buildings), leading to a consequent increase of the seismic demand (design) level. This means that the buildings are firstly designed as ordinary residential structures, then as strategic structures such as hospitals, firefighter station, police station, etc. According to NTC 2018 [11], the variation of the Importance Class involves a different coefficient, indicated as $\mathrm{C}_{\mathrm{u}}$, on which the value of the Reference Period $\left(\mathrm{V}_{\mathrm{R}}\right)$ of the building, and consequently of the Return Period $\left(T_{R}\right)$ of the seismic demand at different limit states, depends. Thus, in practical terms, this coefficient modifies the design response spectra.

Then, in terms of technology, two different types of structural connections are studied: 1) the traditional/monolithic cast-in-situ system and 2) the hybrid low-damage PRESSS solution. The monolithic connections consist of steel reinforcement (steel B450C) within the structural members (concrete C 45/55) and are designed according to the NTC 2018 [11], while the hybrid connections comprise mild steel bars (dissipation) and unbonded post-tensioning tendons (selfcentering).

Furthermore, the case-study buildings are designed referring to three different seismic zones located in Italy: Fabrica di Roma (low seismicity, PGA $=0.15 \mathrm{~g}$ ), Subbiano (moderate seismicity, $\mathrm{PGA}=0.25 \mathrm{~g}$ ) and Reggio Calabria (high seismicity, PGA $=0.35 \mathrm{~g}$ ), selected according to their PGA at the Ultimate Limit State (ULS). Moreover, when the DDBD is adopted, three alternative levels of target drift ratios, namely $1 \%, 1.5 \%, 2 \%$, are identified to analyze the structural behavior and the economic losses when targeting different level of drift.

Therefore, a total of 37 parametric building configurations are employed. Analytical/numerical investigations are developed to analyze the building performance of all case-studies. Then, for each configuration, construction costs (material and labour costs) are computed to determine the short-term cost of the alternative technological solutions. Finally, loss assessment analyses are performed to obtain the Expected Annual Losses (EAL) following two alternative procedures $[13,14]$. Results are finally compared for all the configurations under consideration in terms of seismic costs at the end of the building service life (50 years). This represents an interesting data for the purpose of the economic comparison, proving that designing for higher levels of safety and resilience is cost-effective, not only beneficial from a seismic performance point of view. In fact, this research will impact with the evidence that the choice of a building system/design strategy should be addressed by its long-term economic convenience. Consequently, highlighting that an improved design approach costs less, would hopefully trigger a step-change in the near future and thus represent a major step forward for the overall society and its well-being.

\section{COST/PERFORMANCE PARAMETRIC STUDY}

\subsection{Case-study buildings}

The case-study is a 5-story Reinforced Concrete building with geometrical configuration as indicated in Figure 3. This structure has been selected from a previous study developed by Bianchi et al. [15]. The first two floors have residential use, while the other two are offices. The structural skeleton consists of seismic resistant four-bay frames in one direction and shear walls in the perpendicular direction. 

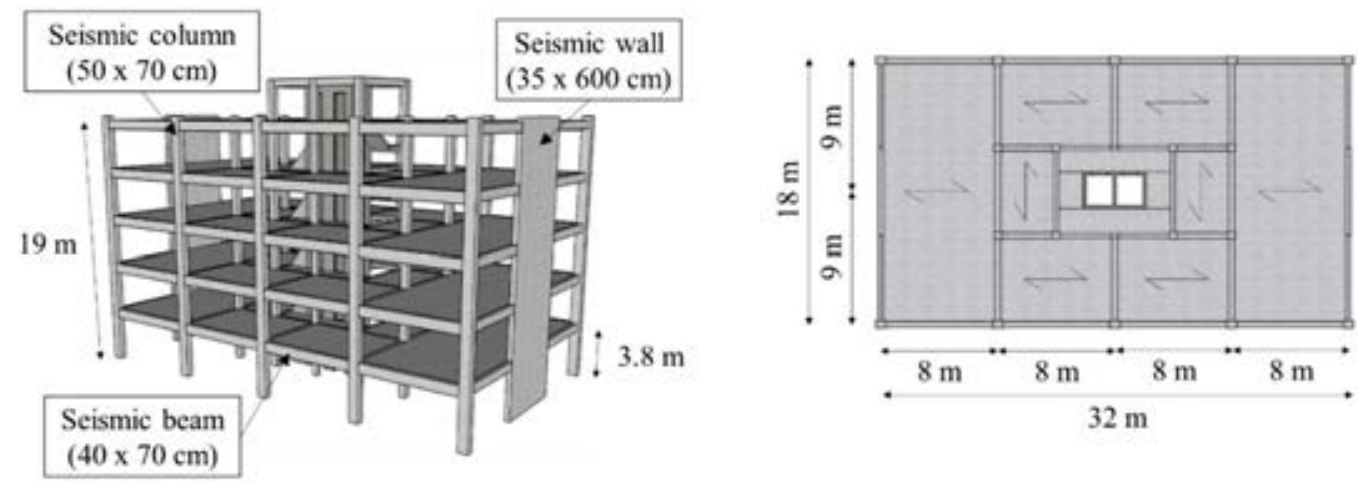

Figure 3: Multi-story case-study RC building (modified after Bianchi et al. 2021).

In this paper, the study is implemented focusing on the frame direction only. As described in the previous section, 37 different combinations of the frame system are considered to develop the proposed investigation. A summary of all the considered frame systems is presented in Table 1. It can be highlighted from this table that the structural cases increase when moving towards a higher seismicity level and importance class. In fact, in these cases the seismic design through the DDBD methodology (the sole to be herein used in case of PRESSS-technology solution) can be developed referring to different (and higher) drift targets.

\begin{tabular}{|c|c|c|c|c|c|c|}
\hline \multirow[b]{2}{*}{ Seismicity level } & \multicolumn{6}{|c|}{ Importance Class } \\
\hline & \multicolumn{2}{|c|}{ II } & \multicolumn{2}{|c|}{ III } & \multicolumn{2}{|c|}{ IV } \\
\hline \multirow{3}{*}{ Low } & & FBD & & FBD & & FBD \\
\hline & Monolithic & $\begin{array}{l}\text { DDBD } \\
(0.8 \%)\end{array}$ & Monolithic & $\begin{array}{l}\text { DDBD } \\
(0.8 \%)\end{array}$ & Monolithic & $\begin{array}{l}\text { DDBD } \\
(0.8 \%)\end{array}$ \\
\hline & PRESSS & $\begin{array}{l}\text { DDBD } \\
(0.8 \%)\end{array}$ & PRESSS & $\begin{array}{l}\text { DDBD } \\
(0.8 \%)\end{array}$ & PRESSS & $\begin{array}{l}\text { DDBD } \\
(0.8 \%)\end{array}$ \\
\hline \multirow[t]{2}{*}{ Moderate } & Monolithic & $\begin{array}{l}\text { FBD } \\
\text { DDBD } \\
(1.0 \%)\end{array}$ & Monolithic & $\begin{array}{l}\text { FBD } \\
\text { DDBD } \\
(1.0 \%)\end{array}$ & Monolithic & $\begin{array}{l}\text { FBD } \\
\text { DDBD } \\
(1.0 \%)\end{array}$ \\
\hline & PRESSS & $\begin{array}{l}\text { DDBD } \\
(1.0 \%) \\
\end{array}$ & PRESSS & $\begin{array}{l}\text { DDBD } \\
(1.0 \%) \\
\end{array}$ & PRESSS & $\begin{array}{l}\text { DDBD } \\
(1.0 \%)\end{array}$ \\
\hline \multirow{6}{*}{ High } & \multirow{3}{*}{ Monolithic } & \multirow{3}{*}{$\begin{array}{l}\text { FBD } \\
\text { DDBD } \\
(1.0 \%) \\
\text { DDBD } \\
(1.5 \%)\end{array}$} & \multirow{3}{*}{ Monolithic } & $\begin{array}{l}\text { FBD } \\
\text { DDBD } \\
(1.0 \%)\end{array}$ & \multirow{3}{*}{ Monolithic } & $\begin{array}{l}\text { FBD } \\
\text { DDBD } \\
(1.0 \%)\end{array}$ \\
\hline & & & & $\begin{array}{l}\text { DDBD } \\
(1.5 \%)\end{array}$ & & $\begin{array}{l}\text { DDBD } \\
(1.5 \%)\end{array}$ \\
\hline & & & & $\begin{array}{l}\text { DDBD } \\
(2.0 \%)\end{array}$ & & $\begin{array}{l}\text { DDBD } \\
(2.0 \%)\end{array}$ \\
\hline & \multirow{3}{*}{ PRESSS } & \multirow{3}{*}{$\begin{array}{l}\text { DDBD } \\
(1.0 \%) \\
\\
\text { DDBD } \\
(1.5 \%)\end{array}$} & & $\begin{array}{l}\text { DDBD } \\
(1.0 \%)\end{array}$ & \multirow{3}{*}{ PRESSS } & $\begin{array}{l}\text { DDBD } \\
(1.0 \%)\end{array}$ \\
\hline & & & PRESSS & $\begin{array}{l}\text { DDBD } \\
(1.5 \%)\end{array}$ & & $\begin{array}{l}\text { DDBD } \\
(1.5 \%)\end{array}$ \\
\hline & & & & $\begin{array}{l}\text { DDBD } \\
(2.0 \%)\end{array}$ & & $\begin{array}{l}\text { DDBD } \\
(2.0 \%)\end{array}$ \\
\hline
\end{tabular}

Table 1: Selected frame configurations. 


\subsection{Design methodology}

The case-study structures are designed at ULS level following two different methodologies: Force-Based Design (FBD) and Displacement-Based Design (DDBD). Taking into account the three different low-to-high seismicity zones (Figure 4a) as well as the three Importance Classes (II, III, IV) described in NTC 2018 [11], accounting for the importance of the building and providing a coefficient $(1.0,1.5,2.0)$ which increases/decreases the seismic action, 9 alternative configurations are designed in case of FBD. As an example, Figure $4 \mathrm{~b}$ presents the response spectra obtained for the case of high seismicity zone and varying the Importance Class.

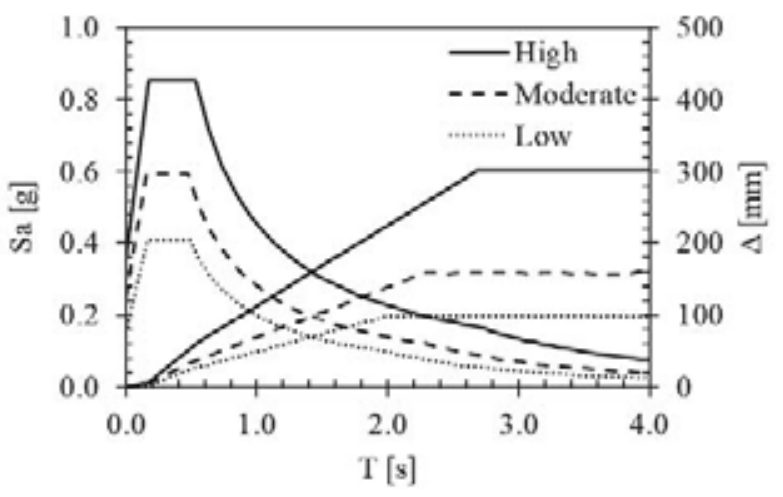

a)

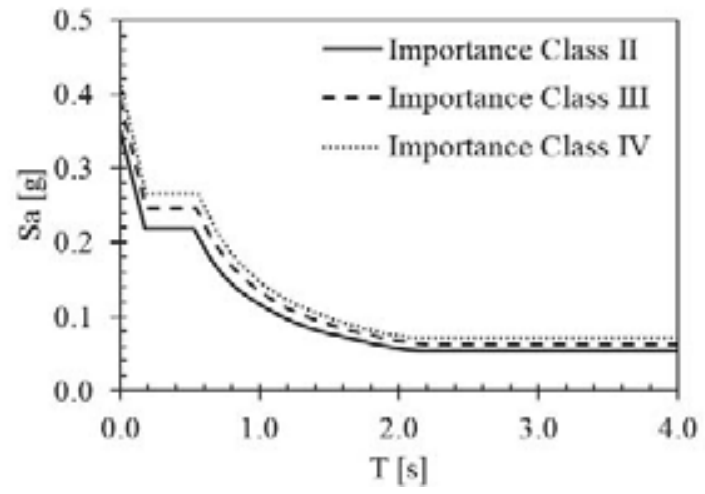

b)

Figure 4: a) Elastic (5\% damped) acceleration and displacement response spectra for the three different seismic zones; b) design acceleration response spectra for the case of high seismicity and varying the Importance Class.

Following the NTC 2018 [11] procedure, the design acceleration response spectra at ULS are obtained from the $5 \%$ elastic spectra properly scaled by the behaviour factor (i.e. $\mathrm{q}=3.9$, for multi-storey frame reinforced concrete structures with regular height and plan, ductility class B). Thus, the base-shear is calculated by multiplying the spectral acceleration at the first natural period of the structure $\left(\mathrm{T}_{1}=0.68 \mathrm{~s}\right.$, function of the building height $H$ and a coefficient $C$ based on the structural typology) and the building mass $(1,2)$. Table 2 summaries the seismic response of the case-studies (monolithic) designed following the codified FBD approach.

$$
\begin{gathered}
T_{1}=C \cdot H^{3 / 4} \\
V_{b}=S_{a}\left(T_{1}\right) \cdot m
\end{gathered}
$$

\begin{tabular}{ccc}
\hline $\begin{array}{c}\text { Seismicity } \\
\text { level }\end{array}$ & $\begin{array}{c}\text { Importance } \\
\text { Class }\end{array}$ & $\begin{array}{c}\text { Base Shear } \\
{[\mathbf{k N}]}\end{array}$ \\
\hline \multirow{3}{*}{ Low } & II & 1206 \\
& III & 1391 \\
& IV & 1523 \\
\hline \multirow{3}{*}{ Moderate } & II & 1705 \\
& III & 1925 \\
& IV & 2122 \\
\hline \multirow{3}{*}{ High } & II & 2826 \\
& III & 3397 \\
& IV & 3785 \\
\hline
\end{tabular}

Table 2: Configurations designed by the FBD approach. 
Concerning the DDBD, the procedure consists in the evaluation of the equivalent building Single Degree of Freedom (SDoF) system with effective elastic stiffness ( $K_{\text {eff }}$ ), effective mass $\left(m_{\text {eff }}\right)$, effective height $\left(H_{\text {eff }}\right)$ and equivalent viscous damping related to the target displacement $\left(\Delta_{d}\right)$. Appropriate design inter-story drift limits are selected based on design code, good practice and/or material strain limits. Table 3 summarizes the various configurations designed following the DDBD approach, by reporting the design drift level, the effective period as well as the base shear, calculated as per $(3,4)$.

$$
\begin{gathered}
K_{e f f}=\left(2 \pi / T_{e f f}\right)^{2} \cdot m_{e f f} \\
V_{b}=\Delta_{d} \cdot K_{e f f}
\end{gathered}
$$

\begin{tabular}{|c|c|c|c|c|c|}
\hline \multirow[b]{2}{*}{$\begin{array}{c}\text { Seismicity } \\
\text { level }\end{array}$} & \multirow[b]{2}{*}{$\begin{array}{c}\text { Importance } \\
\text { Class }\end{array}$} & \multicolumn{2}{|c|}{ Monolithic } & \multicolumn{2}{|c|}{ PRESSS } \\
\hline & & $\begin{array}{c}\text { Design Drift } \\
{[\%]}\end{array}$ & Base Shear [kN] & $\begin{array}{c}\text { Design Drift } \\
{[\%]}\end{array}$ & $\begin{array}{c}\text { Base Shear } \\
{[\mathrm{kN}]}\end{array}$ \\
\hline \multirow{3}{*}{ Low } & II & 0.8 & 1797 & 0.8 & 1865 \\
\hline & III & 0.8 & 1867 & 0.8 & 1977 \\
\hline & IV & 0.8 & 1903 & 0.8 & 2161 \\
\hline \multirow{3}{*}{ Moderate } & II & 1.0 & 2004 & 1.0 & 2101 \\
\hline & III & 1.0 & 2006 & 1.0 & 2111 \\
\hline & IV & 1.0 & 2269 & 1.0 & 2505 \\
\hline \multirow{8}{*}{ High } & II & 1.0 & 2415 & 1.0 & 3264 \\
\hline & II & 1.5 & 2274 & 1.5 & 3008 \\
\hline & III & 1.0 & 3281 & 1.0 & 4468 \\
\hline & III & 1.5 & 2874 & 1.5 & 3763 \\
\hline & III & 1.8 & 2218 & 1.8 & 2989 \\
\hline & IV & 1.0 & 3660 & 1.0 & 5822 \\
\hline & IV & 1.5 & 3340 & 1.5 & 4614 \\
\hline & IV & 2.0 & 2583 & 2.0 & 3041 \\
\hline
\end{tabular}

Table 3: Configurations designed by the DDBD approach.

\subsection{Numerical investigation}

Numerical non-linear static (push-over, push-pull) analyses are carried out in SAP2000 software following a lumped-plasticity approach. The monolithic buildings are modelled by monodimensional elastic elements with plastic hinges at the end sections, where the inelasticity is represented by appropriate moment-curvature relationships and stiffness-degrading hysteresis rules (Takeda). The PRESSS connections are modelled using elastic members with two rotational springs working in parallel at the connection interfaces; 1) one simulating the re-centering contribution from the unbonded post-tensioning tendons (non-linear elastic hysteresis), 2) the other one representing the energy dissipation contribution from the mild steel dissipaters (elasto-plastic or bilinear hysteresis). 
Non-linear static (pushover) analyses are performed to determine the building capacity curves, then converted into acceleration-displacement functions within an Acceleration Displacement Response Spectra (ADRS) domain. Introducing in the same graphs the code-design spectra and applying the Capacity Spectrum Method (CSM) [16, 17], with the building equivalent viscous damping being derived from push-pull analyses, the maximum expected seismic displacements and accelerations (performance) at each intensity level (namely SLO, SLD, SLV, SLC, or, Immediate Operational, Damage Control, Life Safety and Collapse Prevention, as indicated in the NTC 2018 [11]) can be identified. As an example, Figure 5 shows the acceleration-displacement performance points for the case of SLV, high seismicity and Importance Class IV.

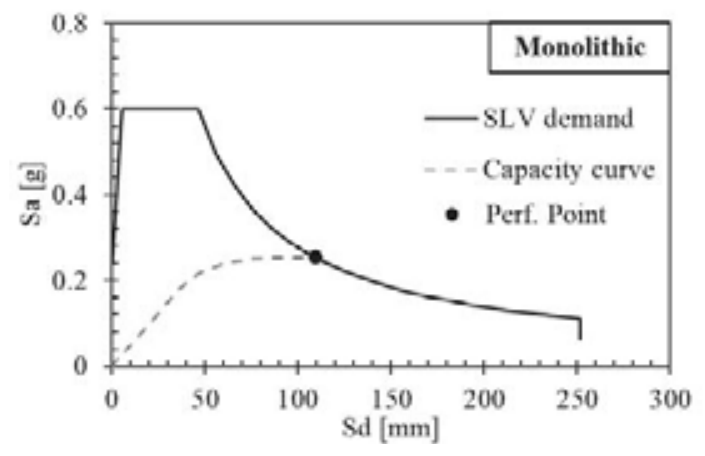

a)

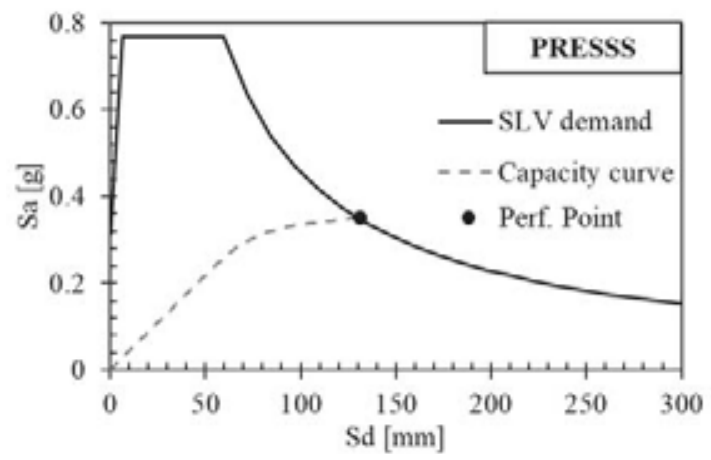

b)

Figure 5: Capacity curves in the Acceleration-Displacement Response Spectrum (ADRS) for both a) Monolithic and b) Low-damage skeletons, high seismicity level (PGA=0.35g), SLV limit state, Importance Class IV.

By comparing the results in terms of base shear for all the case-studies, important considerations supporting the thesis of this paper can be found. Specifically, as presented in Figure 6, ally, the base shear obtained by the FBD has a linear dependence with the Peak Ground Acceleration (PGA) for each seismic zone, however in high seismic zone its value tends to grow faster than the acceleration value. For the cases designed by DDBD, it can be highlighted that the base shear decreases as the design drift increases, due to a greater (accepted) target displacement and thus a lower stiffness, and no direct proportionality between base shear and Peak Ground Acceleration can be found. Furthermore, when considering the hybrid low damage skeleton, a slightly higher base shear - due to the lower hysteretic damping value - is obtained when compared to the traditional solution. This is due to the resisting moment capacity, which is distributed between dissipative and recentring systems, consequently the dissipation is lower when compared to the case of monolithic connections. 


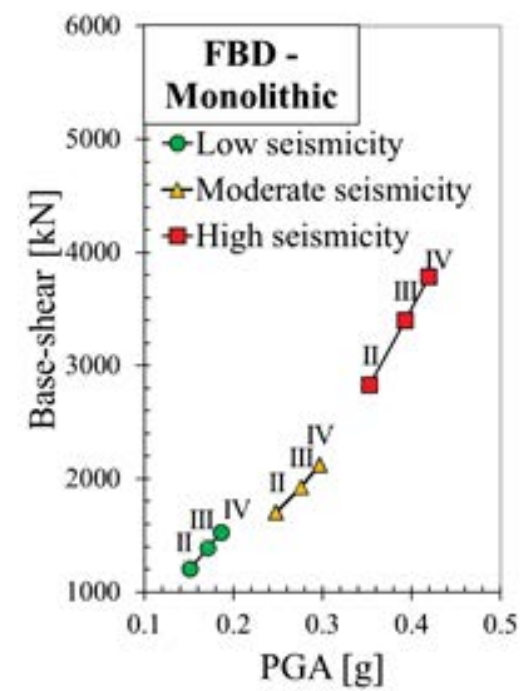

a)

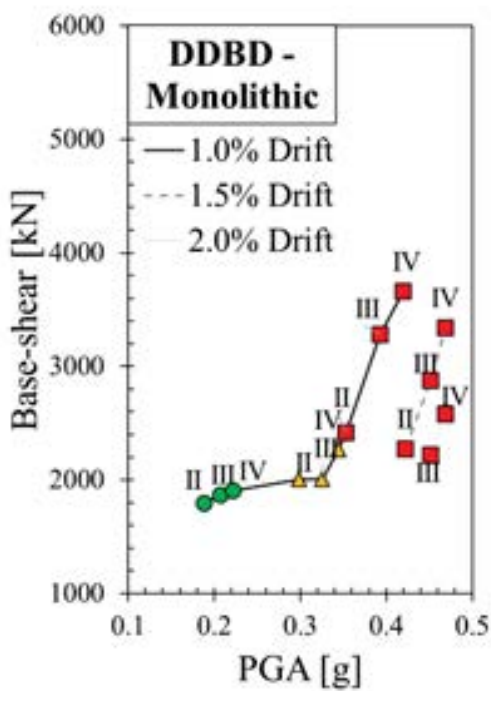

b)

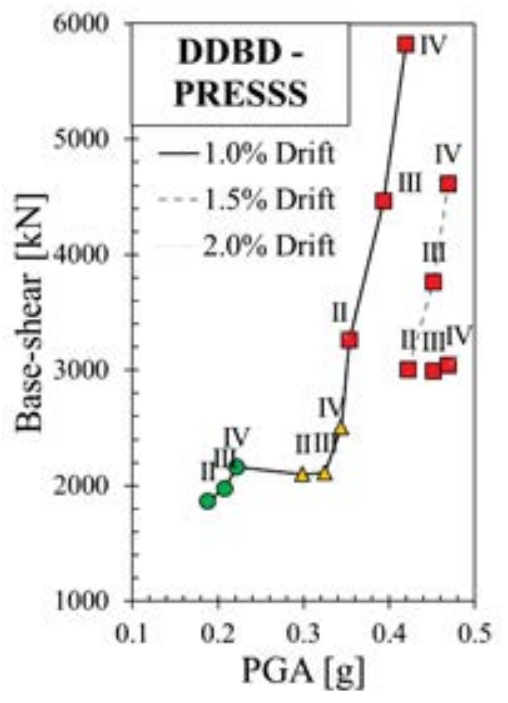

c)

Figure 6: Base shear/PGA curves for: the monolithic structures designed by a) FBD and b) DDBD; c) the low-damage PRESSS structures designed by DDBD (II, III, IV refer to the Importance Class).

Referring to the same seismicity zone, results are also compared by varying the design methodology and type of connection system (Figure 7). Focusing on the monolithic structures, it can be noticed than the FBD underestimates the building base shear in case of low and moderate seismicity zones while overestimate its value in case of high seismicity zone, when compared to the DDBD results, assumed to provide a more reliable ("correct") structural response. This highlights that the FBD method does not allow to have a proper control on the nonlinear behavior of the structure, due to a design procedure based on the selection of a behavior factor, $\mathrm{q}$, representing the dissipation capability of the building under consideration.

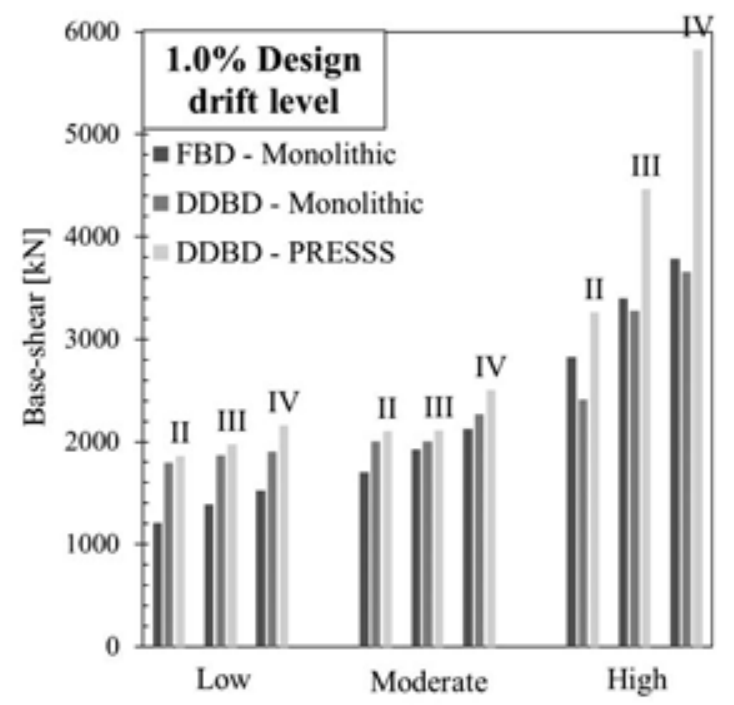

a)

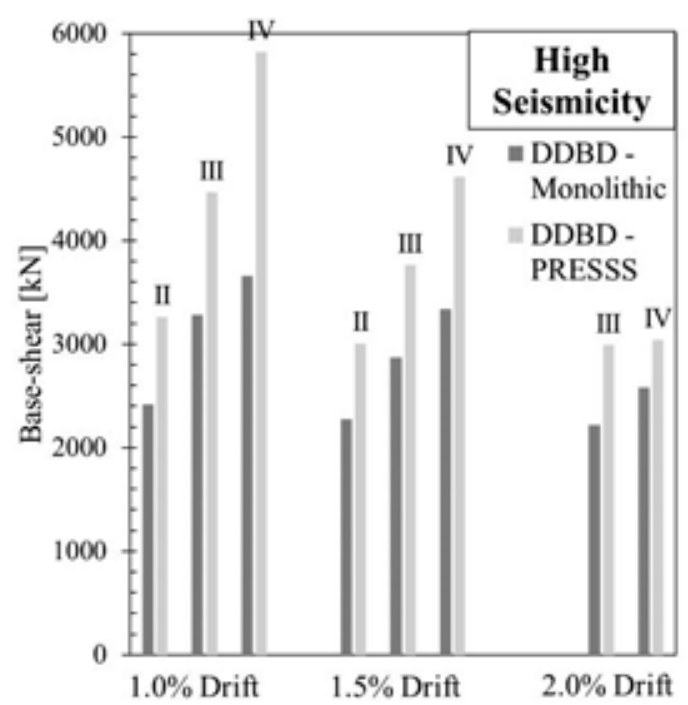

b)

Figure 7: Comparison in terms of Base Shear for: a) alternative design methodologies (at the same design drift level for DDBD) and all the seismicity zones; b) different technological solutions at the same seismicity level, in case of DDBD and various design drift levels. 


\subsection{Construction costs}

For each structural configuration involved, construction costs are computed based on the Regional Public Works Price List of the Friuli-Venezia Giulia region (IT), where the cost of each material already account for the specific labour cost. The cost of the monolithic structure is calculated taking into account the quantities of concrete and steel needed for the structural elements, as well as the cost of formworks, safety, excavation, foundations and geotechnical surveys. For the PRESSS structures, the cost of the tendons and their post-tensioning, the corrugated tube and the crane rental are added to the above items (apart from the cost of in-situ formworks, not needed for the precast elements). In order to define an overall cost of the multistory building, since the seismic-resistant frames have only been designed for the purpose of this study, the other beams, columns and walls have been calculated taking into account code prescriptions and considering standard geometrical dimensions for each element.

A comparison in terms of construction cost for the alternative case-study configurations is reported in the following Figure 8 and Table 4. It can be noticed that the FBD provides costs equal to, or higher than, the DDBD for the same seismicity zone. Moreover, as far as a comparison between technologies is concerned, it can be highlighted that the PRESSS technology leads to an increase of 6.7-8.5\%-in low and moderate high seismic regions with peaks at 12.5$20.20 \%$ in high seismic region, for the construction cost when compared to the monolithic system, due to the presence of tendons/cables and their post-tensioning. In particular, the most expensive cases are those with $1.0 \%$ design drift level in high seismic zone, as confirmed by the results obtained in the previous paragraph in terms of base shear.

Overall for a given seismicity the increase of direct costs associated with a significant raise for the bar, moving from Importance Class II to III and IV, is counter-intuitively rather moderate, ranging between $0.8-2.2 \%, 0.6-3.8 \%, 6 \%-13.3 \%$ in low seismic, moderate seismic and high seismic. Thus arguably, a significant level of higher safety of new construction can be achieved with minimal-moderate investment. In the next paragraph the tangible life-span economic benefits of such approach are investigated.

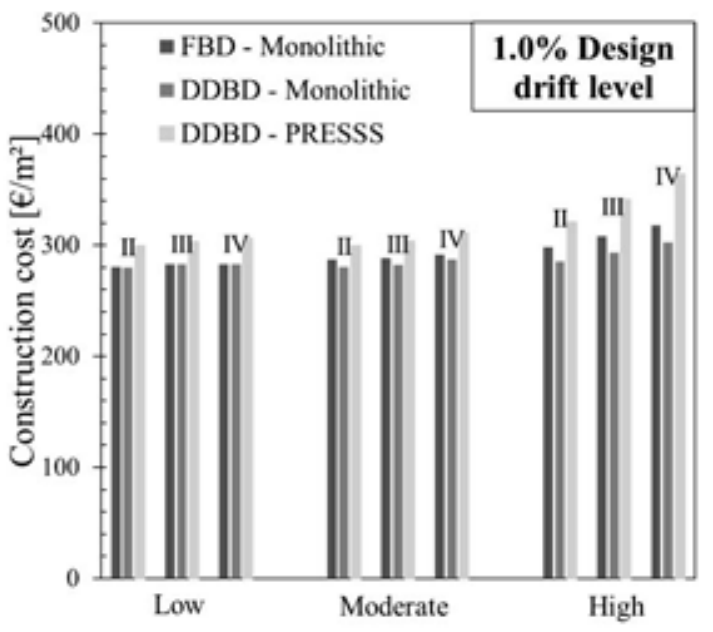

a)

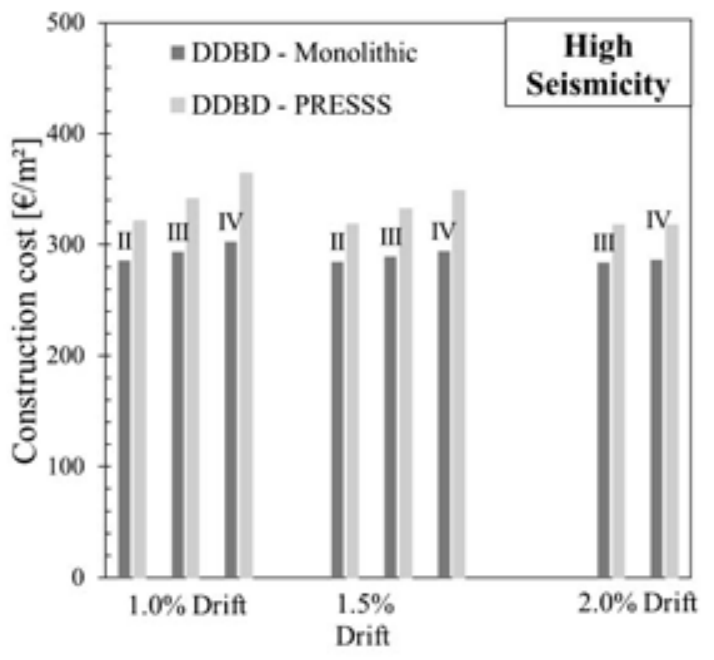

b)

Figure 8: Comparison in terms of Construction Cost for: a) alternative design methodologies (at the same design drift level for DDBD) and all the seismicity zones; b) different technological solutions at the same seismicity level, in case of DDBD and various design drift levels. 


\begin{tabular}{ccccc|cc}
\cline { 3 - 6 } & & \multicolumn{3}{c|}{$\begin{array}{c}\text { Construction Cost } \\
{\left[€ / \mathbf{m}^{2}\right]}\end{array}$} & \multicolumn{2}{c}{$\begin{array}{c}\text { Cost Difference } \\
\text { [\%] }\end{array}$} \\
\hline $\begin{array}{c}\text { Seismicity } \\
\text { level }\end{array}$ & $\begin{array}{c}\text { Importance } \\
\text { Class }\end{array}$ & $\begin{array}{c}\text { FBD } \\
\text { Monolithic }\end{array}$ & $\begin{array}{c}\text { DDBD } \\
\text { Monolithic }\end{array}$ & $\begin{array}{c}\text { DDBD } \\
\text { PRESSS }\end{array}$ & $\begin{array}{c}\text { DDBD } \\
\text { vs FBD } \\
\text { Monolithic }\end{array}$ & $\begin{array}{c}\text { DDBD } \\
\text { Monolithic } \\
\text { VR PRSSS }\end{array}$ \\
\hline \multirow{2}{*}{ Low } & II & 280.7 & 280.0 & 299.8 & 0.25 & 7.06 \\
& III & 282.9 & 282.7 & 303.0 & 0.07 & 7.19 \\
& IV & 282.9 & 282.8 & 306.4 & 0.04 & 8.34 \\
\hline \multirow{2}{*}{ Moderate } & II & 287.0 & 280.8 & 299.6 & 2.21 & 6.68 \\
& III & 288.6 & 282.6 & 303.7 & 2.12 & 7.45 \\
High & IV & 291.8 & 287.3 & 311.5 & 1.57 & 8.44 \\
\hline (1.0\% drift) & II & 298.4 & 285.5 & 321.2 & 4.52 & 12.50 \\
& III & 308.3 & 293.4 & 341.1 & 5.08 & 16.27 \\
\hline
\end{tabular}

Table 4: Comparison in terms of Construction Costs.

\section{LOSS ASSESSMENT ANALYSIS}

The estimation of seismic economic losses is fundamental to evaluate the actual long-term (structure life-span) convenience of a design strategy when compared to another. As mentioned above, the economic aspect is certainly crucial when a project is carried out, and represents the factor mainly addressing the choice of a technological solution. Proving that a safer solution is also the least expensive (when considering the life-span of the building, not only the initial costs) is therefore essential to spread the idea that current traditional performance-based design approach (limited to Life Safety) is not enough to meet the seismic demands of our modern society.

From a procedural point of view, two assessment approaches are herein involved to evaluated the seismic losses and, specifically, to calculate the Expected Annual Losses (EAL), namely: 1) the simplified procedure by D.M. 652017 [13]; 2) the rigorous procedure by FEMA P-58 2012 [14]. The first procedure takes into account the direct losses only and is actually developed for, and calibrated on, existing buildings. On the other hand, the probabilistic FEMA P-58 methodology account for both direct and indirect economic losses, providing an accurate loss estimation if all the building component fragilities (and related fragility curves/consequence functions) are known.

\subsection{Simplified methodology}

The procedure described in the "Seismic Bonus" guidelines - D.M. 652017 [13] - is herein implemented. From the building capacity curves, the capacity Mean Annual Frequencies (MAF) are computed at various seismic intensity levels (SLDI, SLO, SLD, SLV, SLC, SLR, or, respectively Non-structural Damage, Immediate Operational, Damage Control, Life Safety, Collapse Prevention, Demolition and Reconstruction). A Reconstruction Cost is associated with each intensity level and expressed as a percentage of the total building cost. This allows to build the cost/frequency curves and, thus, to determine the EAL value and related class. Since the case-studies are new buildings, the ratio of capacity to demand is equal to (or more than) 1, meaning that the Capacity Return Period is equal to (or more than) the Demand Return Period. The difference between the case-studies is therefore related to the different Importance Class only; as the Importance Class varies, the Return Period associated with each limit state varies. Consequently, only three EAL curves corresponding to the three Importance Classes are obtained for all the 37 cases employed (Figure 9). 


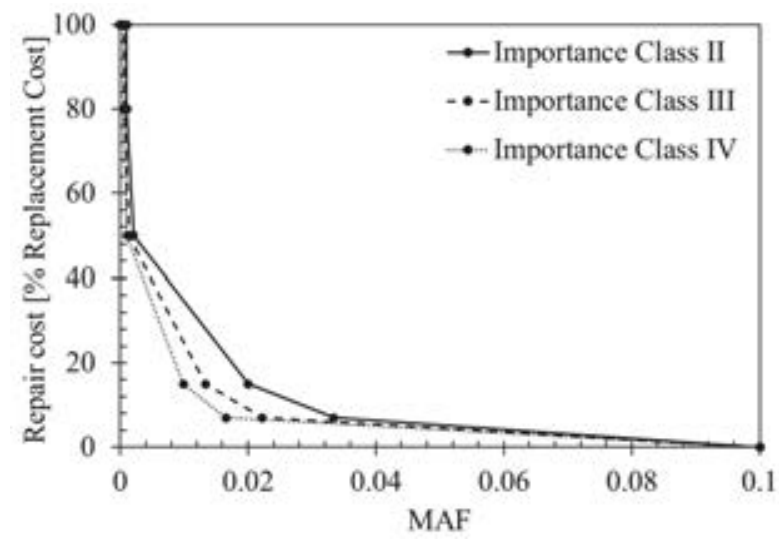

a)

\begin{tabular}{cc}
\hline $\begin{array}{c}\text { Importance } \\
\text { Class }\end{array}$ & $\begin{array}{c}\text { EAL } \\
{[\mathbf{\%} \text { RC }]}\end{array}$ \\
\hline II & 0.98 \\
III & 0.77 \\
IV & 0.66 \\
\hline
\end{tabular}

b)

Figure 9: EAL curves and values obtained from the simplified loss assessment analysis.

In all cases, the building systems result in A class $(0.5 \leq \mathrm{EAL} \leq 1.0)$ and it can be noted that losses are higher when an Importance Class II is assumed, representing the lower safety-resilience level for the building. Therefore, the implemented procedure highlights than the simplified approach, developed for existing structures, is not applicable for new buildings. In fact, it does not allow to account for between different construction methods as well as technologies.

\subsection{Probabilistic-based methodology}

The refined loss assessment investigation is implemented using the PACT (Performance Assessment Calculation Tool) provided by the FEMA P-58 [14]. This practical tool allows to calculate the direct and indirect economic losses of a structure. In order to implement the analysis, input data describing the building (geometry, use, components) and hazard are required. Fragility curves and consequence functions need also to be defined for both structural and nonstructural elements. Concerning the monolithic cast-in-situ connections, the fragility specifications are selected from the ones available in the FEMA P-58 database considering components with similar geometry to the case-study structure. In the case of PRESSS connections, sectionanalysis results are elaborated to build up specific fragility functions describing the connection behavior (i.e. fracture of the mild steel bars and yielding of post-tensioned tendons). Then, the seismic demand for each limit state in terms of inter-story drift ratios and floor accelerations, calculated through the pushover-based capacity spectrum method, are considered as additional input data. Moreover, the analysis is carried out including the contribution of residual drift ratios for the monolithic structures (negligible residual displacements characterize the hybrid system due to its self-centering behavior). The loss assessment analysis thus provides a more accurate estimation of the annualized expected repair costs (EAL values). Figure 10 and Table 5 present the results obtained from this probabilistic-based procedure. 


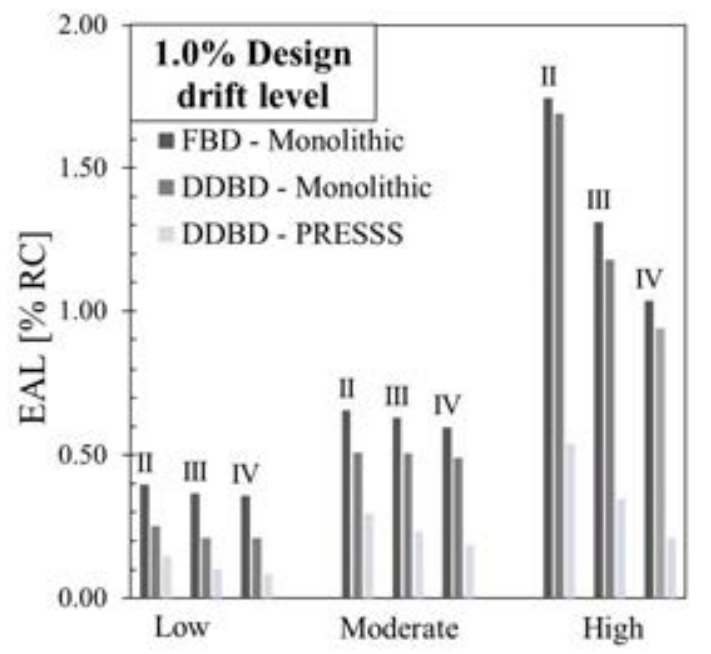

a)

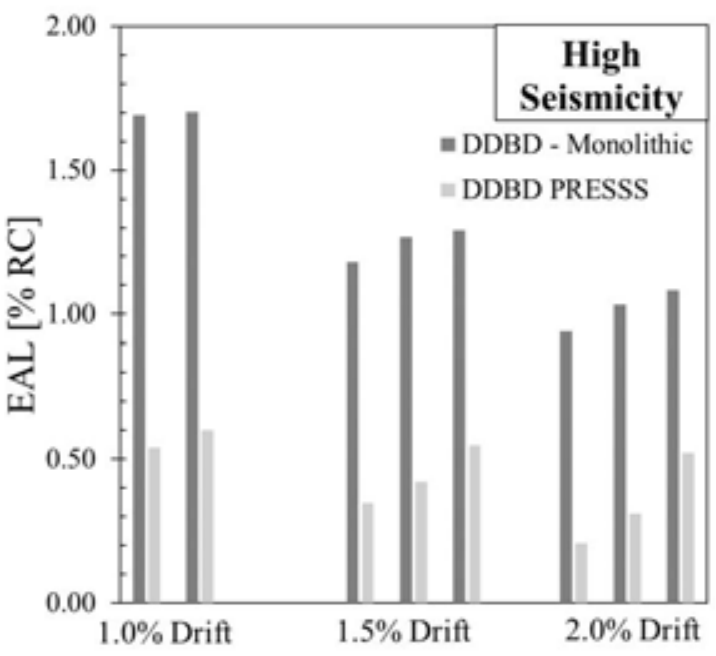

b)

Figure 10: Comparison in terms of Expected Annual Losses for: a) alternative design methodologies (at the same design drift level for DDBD) and all the seismicity zones; b) different technological solutions at the same seismicity level, in case of DDBD and various design drift levels.

\begin{tabular}{cccccc}
\cline { 3 - 5 } $\begin{array}{c}\text { Seismicity } \\
\text { level }\end{array}$ & $\begin{array}{c}\text { Importance } \\
\text { Class }\end{array}$ & $\begin{array}{c}\text { Design Drift } \\
\text { [\%] }\end{array}$ & $\begin{array}{c}\text { FBD } \\
\text { Monolithic }\end{array}$ & $\begin{array}{c}\text { DDBD } \\
\text { Monolithic }\end{array}$ & $\begin{array}{c}\text { DDBD } \\
\text { PRESSS }\end{array}$ \\
\hline \multirow{3}{*}{ Low } & II & 0.76 & 0.40 & 0.25 & 0.14 \\
& III & 0.77 & 0.37 & 0.21 & 0.10 \\
& IV & 0.81 & 0.36 & 0.21 & 0.08 \\
\hline \multirow{3}{*}{ Moderate } & II & 1.0 & 0.66 & 0.51 & 0.30 \\
& III & 1.0 & 0.63 & 0.51 & 0.23 \\
& IV & 1.0 & 0.60 & 0.49 & 0.18 \\
\hline \multirow{3}{*}{ High } & II & 1.0 & 1.74 & 1.69 & 0.54 \\
& II & 1.5 & - & 1.70 & 0.60 \\
& III & 1.0 & 1.31 & 1.18 & 0.35 \\
& III & 1.5 & - & 1.27 & 0.42 \\
& III & 1.8 & - & 1.29 & 0.55 \\
& IV & 1.0 & 1.04 & 0.94 & 0.21 \\
& IV & 1.5 & - & 1.03 & 0.31 \\
& IV & 2.0 & - & 1.08 & 0.52 \\
\hline
\end{tabular}

Table 5: Comparison in terms of Expected Annual Loss.

Results in terms of EAL highlight that: 1) as the service class increases, the losses decrease, due to the increased level of safety consequently leading to reduced seismic losses; 2) as the design drift level increases, the value of EAL parameter also increases; this is related to a seismic design for higher levels of displacement which brings to consequent higher damages. When comparing the results obtained for the same construction technology whilst varying the design method, FBD produces greater losses than the DDBD, confirming the disadvantage of applying such traditional design methodology. Moreover, looking at the different types of skeleton systems, PRESSS structures lead to significantly lower losses when compared to monolithic structures, due to its inherent low-damage nature. 
Referring to the repair costs of each limit state as well as to their Mean Annual Frequency of exceedance, EAL curves are built. These curves provide more reliable loss values when compared to the previous simplified results not accounting for the real repair costs associated with each limit state. The overall repair cost is now properly computed for the various intensity levels and this allows to appreciate the advantages and disadvantages of design methods and technologies. Comparisons in terms of EAL curves are thus carried out for the different seismicity levels as presented in Figure 11 (e.g. different seismicity areas, service class IV, 1.0\% design drift level for DDBD). In the same graph a reparability threshold of $65 \%$, i.e. value above which is no longer considered convenient to repair the building, is also included. It is noted that in low seismicity areas this threshold value is never reached.

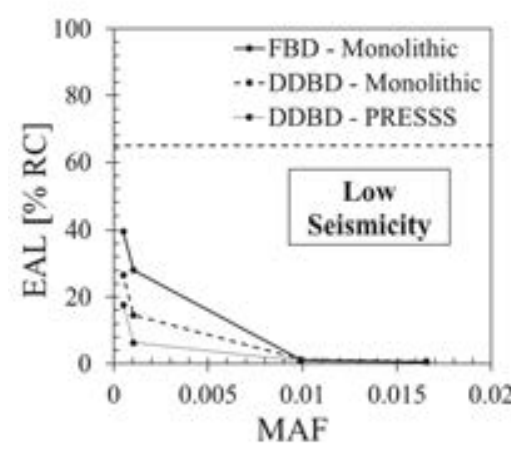

a)

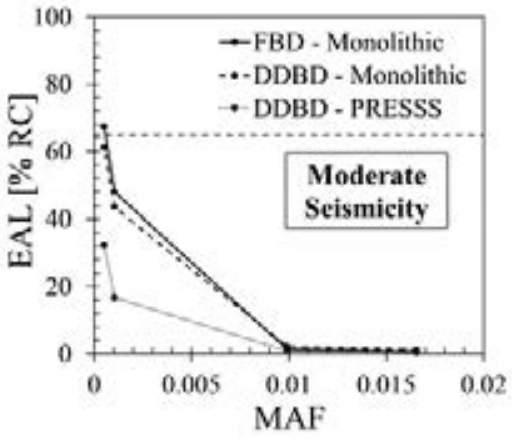

b)

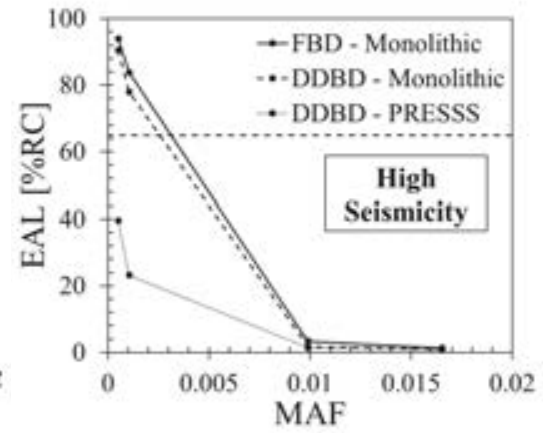

c)

Figure 11: Comparison of design strategies in terms of EAL curves (for different seismic zones: a) low; b) moderate; c) high, an Importance Class IV, 1.0\% design drift level for DDBD).

\section{SEISMIC COSTS IN THE BUILDING LIFE}

In order to better appreciate the advantages of a design based on the control of damage and on increased safety levels, the seismic costs of all case-studies are compared at the end of the service life, that is, for example, 50 years after the building construction. This comparison can be carried out by considering the annualized losses (the EAL parameter) distributed along 50 years in order to evaluate the percentage of construction cost which would be lost at the end of the building life. As shown in Figure 13a, the cumulative seismic cost is described by a linear trend going from the initial cost at the time of construction to the cost at the end of the building service life. The intersection between the different lines, representing different design strategies, identify the break-even time at which the initial (if any) difference in the initial construction costs is balanced; therefore, although at the time of initial construction the PRESSS technology might be slightly more expensive than the traditional one (notably the implementation of actual buildings have proven to be no more expensive), from the year corresponding to the intersection of their cost lines onward, the trend is completely reversed. For example, it can be noticed that in high seismicity and design drift of $1.0 \%$ for DDBD, the difference in the initial cost of $12 \%$ (monolithic vs. low damage) at the time of construction can be fully recovered in just ten years. In order to highlight the advantages obtained by switching from FBD to DDBD as well as from monolithic to hybrid connections, the savings after 50 years from the time of construction and for each seismicity area are shown and compared in Figure $12(b, c)$ and Table 6. 


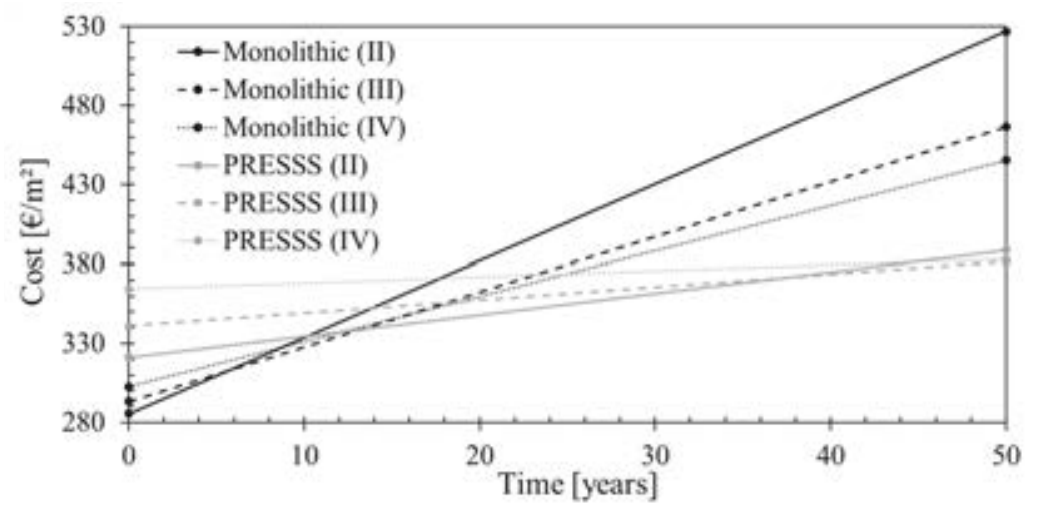

a)

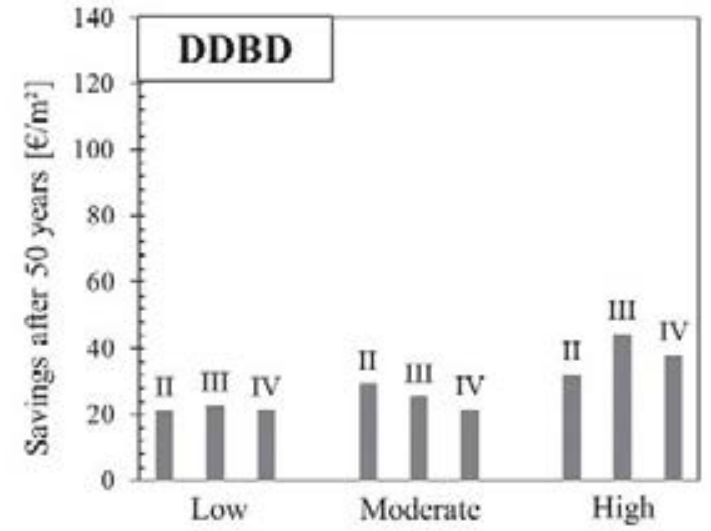

b)

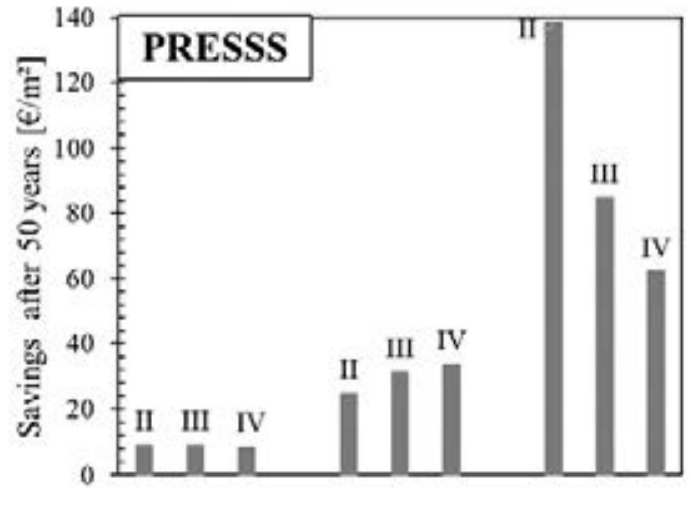

c)

Figure 12: a) Cost/time curves in case of High Seismicity zone; Average savings at the end of the building life for different seismicity zones and due to: b) DDBD method; c) PRESSS technology.

\begin{tabular}{ccccc|cc} 
& & \multicolumn{3}{c|}{$\begin{array}{c}\text { Savings at 50 years } \\
{\left[\mathbf{\epsilon} / \mathbf{m}^{2}\right]}\end{array}$} & \multicolumn{2}{c}{$\begin{array}{c}\text { Savings } \\
{\left[€ / \mathbf{m}^{2}\right]}\end{array}$} \\
\cline { 3 - 7 } $\begin{array}{c}\text { Seismicity } \\
\text { level }\end{array}$ & $\begin{array}{c}\text { Importance } \\
\text { Class }\end{array}$ & $\begin{array}{c}\text { FBD } \\
\text { Monolithic }\end{array}$ & $\begin{array}{c}\text { DDBD } \\
\text { Monolithic }\end{array}$ & $\begin{array}{c}\text { DDBD } \\
\text { PRESSS }\end{array}$ & $\begin{array}{c}\text { DDBD vs } \\
\text { FBD } \\
\text { Monolithic }\end{array}$ & $\begin{array}{c}\text { DDBD } \\
\text { Monolithic } \\
\text { vs PRESSS }\end{array}$ \\
\hline Low & II & 336.3 & 315.2 & 306.1 & 21.1 & 9.1 \\
& III & 334.8 & 312.3 & 303.3 & 22.5 & 9.1 \\
& IV & 333.5 & 312.4 & 304.0 & 21.1 & 8.5 \\
\hline Moderate & II & 381.3 & 352.3 & 327.6 & 29.0 & 24.7 \\
& III & 379.5 & 354.2 & 323.0 & 25.2 & 31.2 \\
& IV & 379.1 & 357.7 & 324.0 & 21.3 & 33.7 \\
\hline High & II & 558.8 & 527.0 & 388.5 & 31.7 & 138.5 \\
& III & 510.6 & 466.4 & 381.5 & 44.1 & 84.9 \\
\hline
\end{tabular}

Table 6: Comparison in terms of savings at the end of the building life.

The savings are clearly more consistent in high seismicity areas and consequently the advantages of a low-damage technology are more evident. The previous graphs are particularly relevant, as it presents in absolute terms the significant amount of (tax-payers) money that can be saved in 50 years. Cost of construction is correlated with losses over time and money savings are evident. Finally, it is observed that the convenience of implementing low-damage technologies is substantial for the case of high seismicity area and Importance Class II. 


\section{CONCLUSIONS}

This paper has focused on the cost/performance-based study and comparison of alternative design strategies which might be adopted to enhance the seismic safety of new buildings. Focusing on Reinforced Concrete structures and considering increasingly levels of seismic intensity (representing either a higher seismic zone or a higher service class or Importance Level), different design methodologies (force-based vs displacement-based) or technologies (monolithic vs low-damage) have been adopted to develop the proposed parametric study.

Results of this research allows for greater awareness of the proper design method/strategy to be used according to the seismic area and the Importance Class of a specific building. In particular, the developed study highlights that the force-based design brings to different (yet not necessarily conservative) results when compared to the displacement-based design. Specifically, the parametric study on alternative structural configurations highlights that the building response in terms of base shear is generally overestimated. However, this does not mean that the force-based design is a more conservative method than the displacement-based approach (as it could in turn underestimate the displacement-ductility demand), while it highlights that this approach does not allow to have a proper control of the real structural behavior, and in general on the obtained seismic results. Furthermore, the parametric study shows that the base-shear, that is a fundamental parameter for the seismic design since it allows to determine the demand moment/shear values on the structural elements, does not necessary nor directly increase with the assumed level of seismic intensity, expressed in terms of Peak Ground Acceleration (PGA). Specifically, looking at the same design displacement, the base shear increases with the acceleration, whilst if the acceleration doubles, the base shear does not. This last consideration proves that designing for higher Importance Classes, and therefore with greater safety and resilience, does not necessarily lead to an equally higher cost. Minor but appropriately focused investments can instead lead to greater safety, resilience and long-term savings.

Taking into account the results in terms of initial construction cost and focusing on high seismicity area, (worst case scenario) it can be noticed that moving from Importance Class II to IV with the same design drift level (e.g. 1\%), although the required base shear should be 50\% higher, an initial cost increase of only $6 \%$ is expected. More importantly, when considering the cumulative seismic cost over time, the slight cost distance is completely recovered in less than 10 years, and at the end of the service life of the structure (50 years) a saving of about $15 \%$ is obtained, leading to an increased safety for the building as well as reduced losses over time.

Furthermore, the advantage related to the implementation of a low-damage technology such as the rocking-dissipative PRESSS system is evident, especially for the case-studies where postearthquake damage causes very high repair costs. In fact, the computed savings at 50 years (service life) after the time of construction show that the greatest savings refer to Importance Class II, design drift of $1 \%$ and high seismicity zone. Importance Class II is, in general, the level with the highest losses over time (lower safety), while a design drift of $1 \%$ presents the most expensive case in terms of construction cost. However, this consideration does not lead to the conclusion that in areas with a low seismicity, low-damage connections are not convenient; savings are obtained for all seismic-prone areas and Importance Classes, so it is clear that designing better, that means for better performance and greater safety, is always also economically convenient leading to a more resilient community.

Despite this research work represents an initial study aiming to prove the convenience of implementing enhanced-safety design strategies, further investigations are needed to compare alternative design methods and technologies. In particular, more refined numerical studies are required, involving time-history analyses and performing a probabilistic-based approach, looking at the influence of the design approach on the building probability of collapse. 


\section{REFERENCES}

[1] W.Y. Kam, S. Pampanin, K. Elwood, Seismic performance of reinforced concrete buildings in the 22 February Christchurch (Lyttelton) earthquake. Bulletin of the New Zealand Society for Earthquake Engineering, 44, 4, 239-278, 2011.

[2] Structural Engineers Associate of California, Performance-based seismic engineering, SEAOC Vision 2000, Sacramento, California, USA, 2000.

[3] S. Pampanin, Reality-check and Renewed challenges in Earthquake Engineering: Implementing low-damage structural Systems - from theory to practice. Bulletin of the New Zealand Society for Earthquake Engineering, 45, 4, 137-160, 2012.

[1] S. Pampanin, Towards the "Ultimate Earthquake-Proof" Building: Development of an Integrated Low-Damage System. Perspectives on European Earthquake Engineering and Seismology (A. Ansal, ed.), Geotechnical, Geological and Earthquake Engineering 39, Springer Nature, Switzerland, 2015.

[2] M.J.N. Priestley, Overview of PRESSS Research Program. PCI Journal, 36, 4, 50-57, 1991.

[3] M.J.N. Priestley, S. Sritharan, J.R. Conley, S. Pampanin, Preliminary Results and Conclusions From the PRESSS Five-Story Precast Concrete Test Building. PCI Journal, 44, $6,42-67,1999$.

[4] S. Pampanin, Emerging solutions for high seismic performance of precast -prestressed concrete buildings. Journal of Advanced Concrete Technologies, 3, 2, 202-222, 2005.

[5] S. Pampanin, D. Marriott, A. Palermo, New Zealand Concrete Society, PRESSS Design Handbook, Auckland, New Zealand, 2010.

[6] F. Sarti, A. Palermo, S. Pampanin, Fuse-Type External Replaceable Dissipaters: Experimental Program and Numerical Modeling. Journal of Structural Engineering, 142, 12, 2016.

[7] International Federation for Structural Concrete (fib), Bulletin No. 27, Lausanne, Switzerland, 2003.

[8] Ministero delle Infrastrutture, Aggiornamento delle Norme Tecniche per le Costruzioni, Supplemento ordinario ${ }^{\circ} 8$ alle G.U. $n^{\circ} 42$ del 20/02/2018, serie generale, Rome, Italy, 2018.

[9] M.J.N. Priestley, G.M. Calvi, M.J. Kowalsky, Direct Displacement-Based Seismic Design of Structures, 1st edition, IUSS Press, Pavia, Italy, 2007.

[10] Ministero delle Infrastrutture, Linee guida per la classificazione del rischio sismico delle costruzioni, Decreto Ministeriale 58 del 28/02/2017, Rome, Italy, 2017.

[11] Federal Emergency Management Agency (FEMA), Seismic Performance Assessment of Buildings, Volume 1 - Methodology. Technical Report FEMA-P-58-1, Washington, D.C., USA, 2012.

[12] S. Bianchi, J. Ciurlanti, S. Pampanin, Comparison of traditional vs low-damage structural and non-structural building systems through a cost/performance-based evaluation. Earthquake Spectra, 37, 1, 366-385, 2021. 
[13] S.A. Freeman, Review of the development of the capacity spectrum method. ISET J. Earthquake Technology, 41, 1, 1-13, 2004

[14] Applied Technology Council (ATC), Seismic evaluation and retrofit of concrete buildings. ATC 40, Redwood City, CA, USA, 1996. 